\title{
ISW Treatment for Skeletal Class III Malocclusion with Poor Arch Coordination
}

\author{
Chih-Chieh LIN ${ }^{1}$, Chien-Chih YU*2, Chun-Shuo HUANG ${ }^{3}$ and Jian-Hong YU ${ }^{3,4}$ \\ ${ }^{1}$ Department of General Dentistry, China Medical University Hospital, Taiwan \\ ${ }^{2}$ School of Pharmacy, China Medical University, Taiwan \\ ${ }^{3}$ Department of Orthodontics, China Medical University Hospital, Taiwan \\ ${ }^{4}$ School of Dentistry, College of Dentistry, China Medical University, Taiwan
}

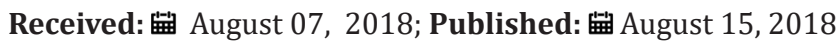

*Corresponding author: Chien-Chih YU, School of Pharmacy, China Medical University, Taiwan

\begin{abstract}
An adult female (30 years old) came to our clinic with a chief complaint about not able to chew food well and bilateral posterior crossbite. Clinical examination revealed skeletal Class III malocclusion with posterior crossbite and poor arch coordination. Due to her refusal to receive orthognathic surgery, non-surgical treatment was adopted. With successful width decrease of lower arch by two 1st molars extraction; then mesial drive of two 2nd and 3rd molars with closed coil spring, Class III malocclusion was corrected by ISW technique combined with Class III elastics. Treatment was completed in about 18 months and a desirable occlusion after the active treatment was achieved.
\end{abstract}

Keywords: ISW; Posterior Crossbite; Molar Mesial Drive; Intermaxillary Elastics (IME); Closed Coil Spring

\section{Introduction}

Coordination between the upper and lower arches is one of the most important aspects of achieving stable functional and esthetic results during orthodontic treatment. Because a transverse discrepancy could induce an adverse periodontal response, unstable dental camouflage, and functional and esthetic problems, maintenance of an adequate overjet during treatment should be essential [1-6]. ISW (improved super-elastic Ti-Ni alloy wire, developed by Tokyo Medical and Dental University) for nonsurgical treatment of adult skeletal Class III malocclusion with poor arch coordination will be discussed.

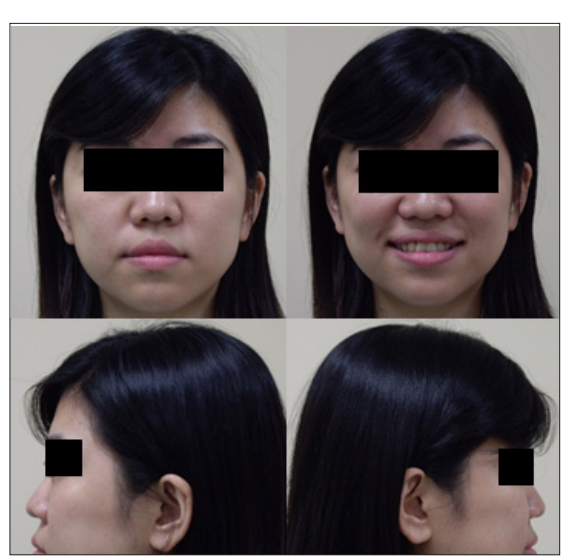

Figure 1: Facial photos before active treatment.

\section{History and Diagnosis}

An adult female (26 years old) came to our clinic with a chief complaint of not able to chew food well and bilateral posterior crossbite. Her lateral profile was concave, and the frontal view showed slightly facial asymmetry phenomenon (Figure 1). Clinical examination revealed bilateral Class III molar relationship, right canine class III tendency with left canine class I relationship, bilateral posterior crossbite, and mild crowding over lower anterior teeth with mandibular shift to right side resulting in facial asymmetry (Figure 2). Panoramic film showed \#28, \#38, \#48 existence (Figure 3).

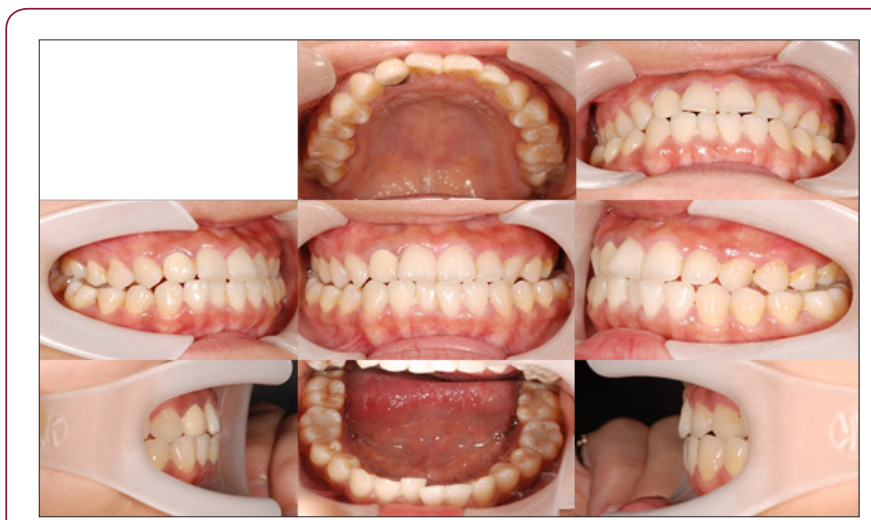

Figure 2: Intraoral photos before active treatment. 


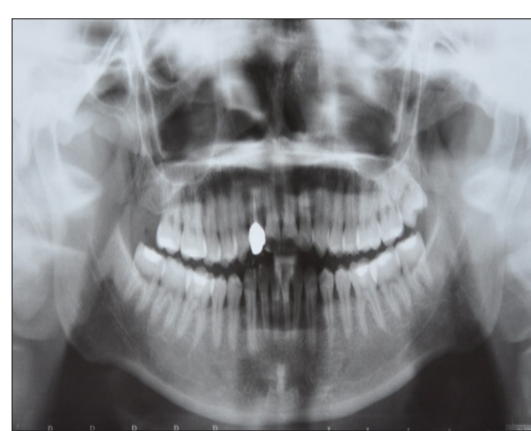

Figure 3: Panoramic film before active treatment.

This patient refused to receive orthognathic surgery, so we decided to adopt non-surgical orthodontic treatment. LH (Low Hysteresis Improved Super-elastic Ti-Ni alloy wire, developed by Tokyo Medical and Dental University) technique with mesial drive of two 2nd and 3rd molars mesial drive of closed coil spring successfully decreases the width of lower arch by two 1st molars extraction, Class III malocclusion was corrected by ISW technique combined with Class III elastics. Treatment was completed within 18 months and a desirable occlusion with adequate overbite and overjet was achieved. The cephalometric analysis showed a skeletal class III jaw relationships (SNA: $74.9^{\circ}$ : SNB: $75.6^{\circ}$ : ANB: $-0.6^{\circ}$ ) and dental compensation (U-1 to FH plane: $119.7^{\circ}: \mathrm{L}-1$ to mandibular plane: 92.8 ${ }^{\circ}$ (Figure 4). P-A (postero-anterior) cephalometric radiograph showed mandibular discrepancy between the right and the left ramus heights (Right side:47.5mm:Left side:48.5mm, ramus discrepancy:0mm) (Figures 5 \& 6).

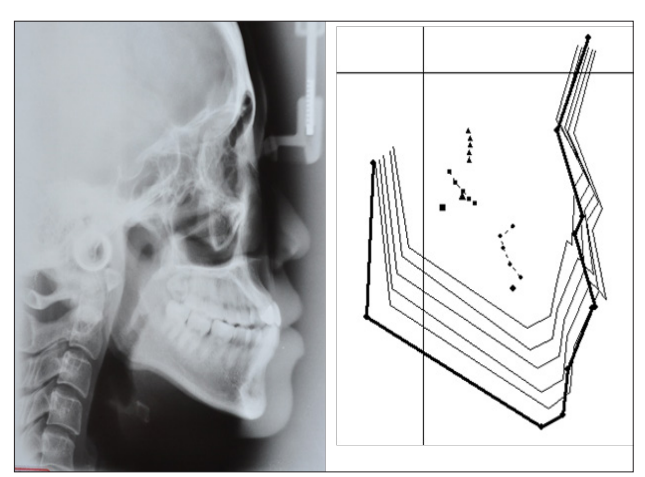

Figure 4: Lateral cephalometric film before active treatment.

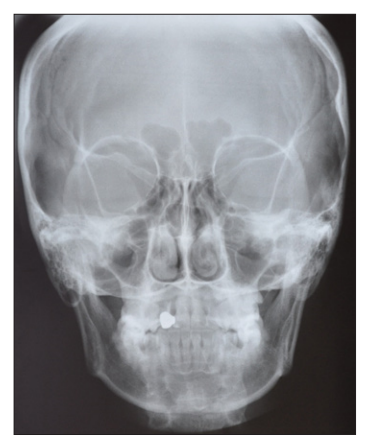

Figure 5: Postero-anterior (PA) film before active treatment.

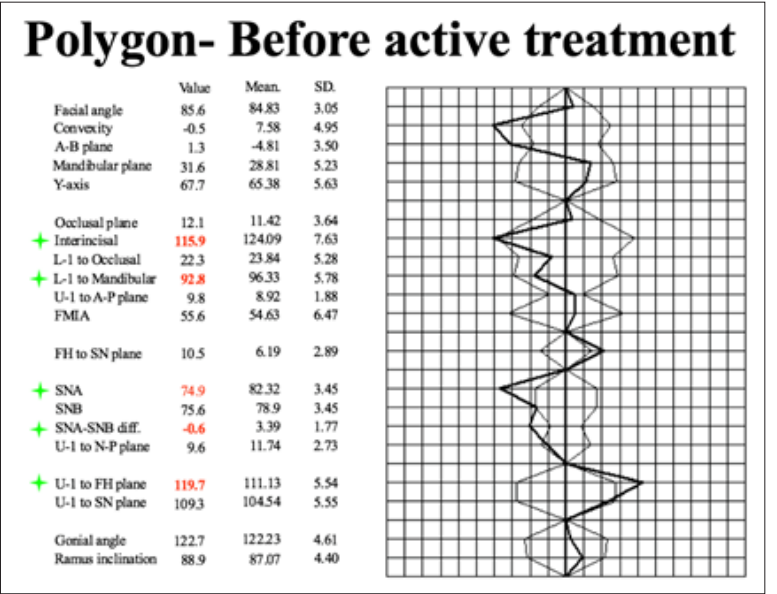

Figure 6: Polygon before active treatment.

Therefore, the summary of diagnosis includes:

a) Functional (-):

b) Skeleta l (+): skeletal Class III

c) Denture (+): upper incisor labial tipping

d) Dental (+) :12 endo-treated with crown:\#28,38,48 existence

e) Discrepancy (+): upper: R't: $-1.5 \mathrm{~mm} / \mathrm{L} t \mathrm{t}:-1.3 \mathrm{~mm}$; lower: R't:- $2.0 \mathrm{~mm}$

The radiographic methods of the research include intraoral photos, posteroanterior cephalometric projection, lateral cephalometric projection and panoramic x-ray films. Also, the cephalometric analyses before and after the treatment were presented in this case. About the treatment plan, full-mouth DBS (Direct Bonding System) and the method of leveling with $0.016 \mathrm{x}$ $0.022 \mathrm{LH}$ were used from the start of active treatment, and elastic chain was also used between $35 \& 37$ and $45 \& 47$. And then, for mesial drive of \#37,47, closed coil springs (100 gf) were set over crimpable hook-37 and crimpable hook-47. Intermaxillary elastics was also set to facilitate $37 \& 47$ mesial drive and uprighting. Torque control of \#36,37,46,47 was subsequently perfomed and $\# 36,37,46,47$ were re-DBS with \#16,17,26,27 brackets, $0.018 \mathrm{x}$ 0.025 ISW was placed to reinforce the torque control to the lower dentition. For the finishing and detailing of the case, Re-DBS of \#41,42 for better rotation control. IME was set between 14 to 47 and 24 to 37 for interdigitation and tripping was performed over 32 to 42 for reduction of black triangle. Crown lingual torque was added on \#38 and reverse curve was set in the lower dentition. After debonding, a circumferential retainer was delivered for the upper arch and a Hawley retainer for the lower arch was used for the retention.

The analysis showed a skeletal Class III with bilateral posterior crossbite. L1 to mandibular plane angle showed a severe labially tipped upper incisor and slightly lingually tipped lower incisor, to correct the poor arch coordination lower bilateral first molar must be extracted to decrease the lower arch length efficiently. 


\section{Treatment Objectives}

Our treatment objectives were (1) to correct disharmony arch coordination, (2) to improve facial profile (3) to establish appropriate overbite, overjet and arch coordination, (4) to establish indivualized occlusion

Due to the fact that the patient strongly refused the possibility of orthognathic surgery. Therefore, treatment plan includes:

a) \#36,46 extraction

b) Full mouth DBS (Patient refused OGS.)

c) ISW leveling for correction of anterior/posterior crossbite

d) Closed coil spring \& IME for \#37,38,47,48 mesialization

e) Torque control for \#37,38,47,48 mesialization by using brackets of \#26,27,16,17

\section{Treatment Progress}

Treatment was started from 2008.07.22 with full mouth DBS, leveling with 0.016 x 0.022 ISW. Elastic chain was set between 35 \& 37 and $45 \& 47$ (Figure 7).

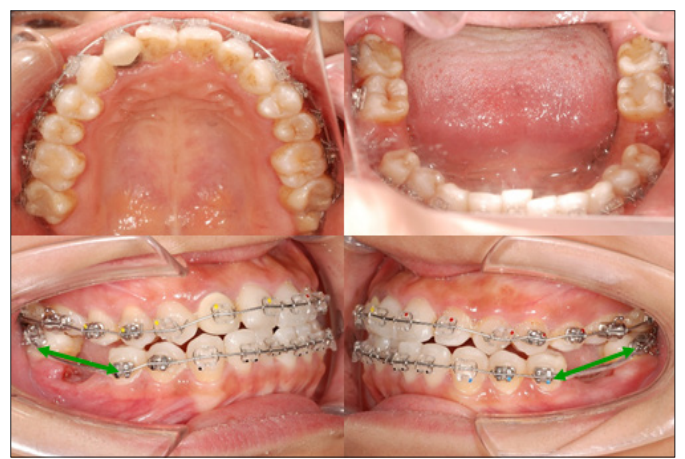

Figure 7: Period of active treatment: 0 month.

On 2008.09.01. Closed coil springs (100 gf) were set over crimpable hook-37 and crimpable hook-47 and intermaxillary elastics was set to facilitate $37 \& 47$ mesial drive and uprighting (Figure 8).

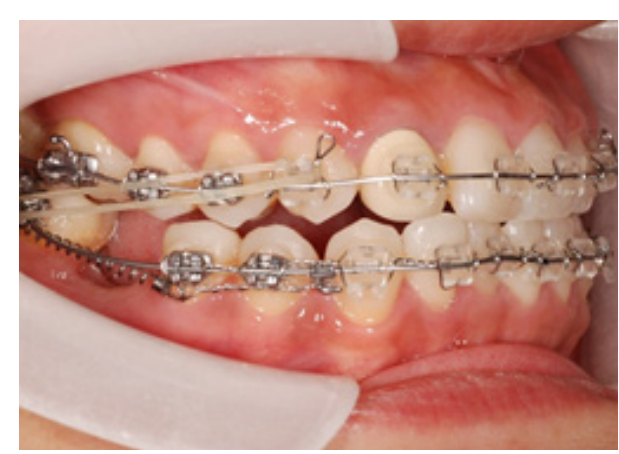

Figure 8: Period of active treatment:1 month.

On 2008-12-07, after 6 months of active treatment, intermaxillary elastics was set between \#13 to 47 and \#23 to 37 . Closed coil springs (100 gf) were set over crimpable hook-38 and crimpable hook-48. Elastic chain for \#37,47 mesial drive Buccal offset was also set for torque control of \#12 (Figure 9).

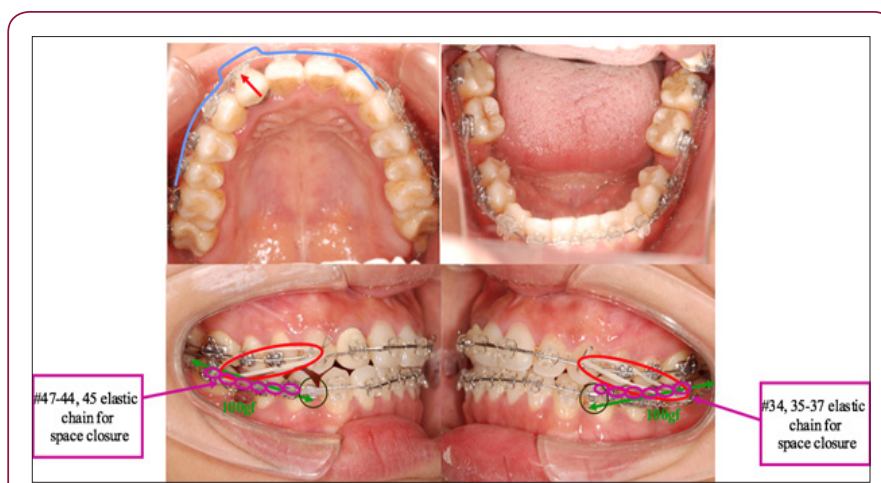

Figure 9: Period of active treatment: 6 months.

On 2009-02-03, expansion Arch was set for correction of 37 \& 47 lingual tipping. And intermaxillary elastics was set to facilitate $37 \& 47$ up righting (Figure 10).

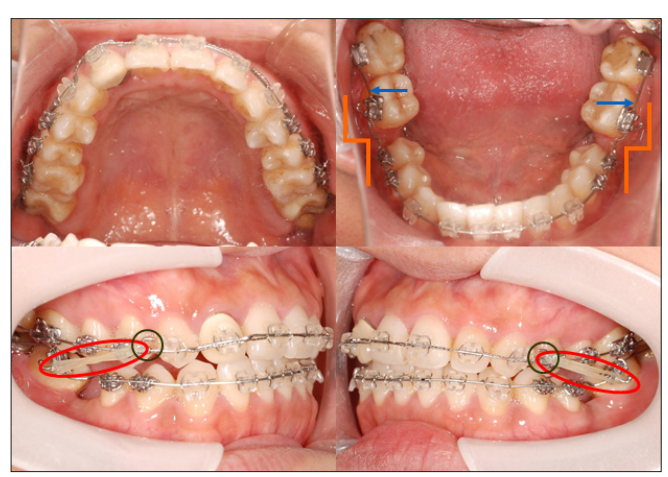

Figure 10: Period of active treatment: 7 months.

After 7 months of active treatment, on 2009-06-11,\#36,37,46,47 were re-DBS with \#16,17,26,27 brackets. And 0.018 x 0.025 ISW was also placed in the lower dentition (Figure 11).

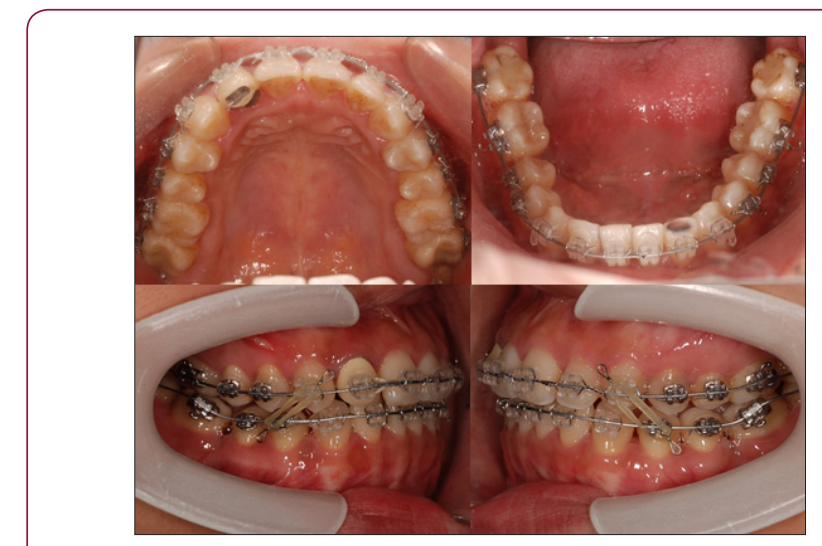

Figure 11: Period of active treatment: 13 months.

\section{Treatment Results}

After 18 months of active treatment, for the final finishing and detailing stage, on 2009-12-07, Re-DBS of \#41,42 was performed for better rotation control. IME was set between 14 to 47 and 24 to 37 for interdigitation, and stripping was performed over 32 to 42 for reduction of black triangle. Crown lingual torque was also added on \#38 and reverse curve was set in the lower dentition (Figure 12). 


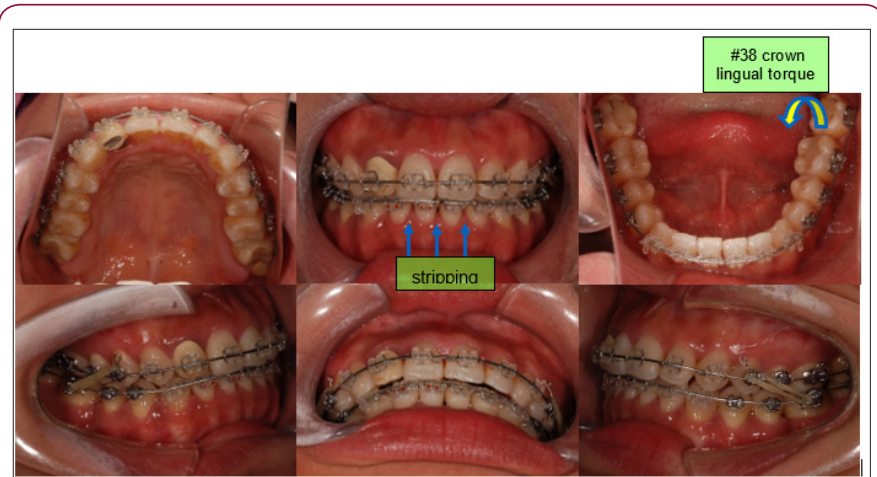

Figure 12: Period of active treatment: 16 months.

On 2010-01-27, debonding of full mouth bracket was performed and circumferential retainer was delivered for the upper arch and Hawley retainer for the lower (Figure 13).

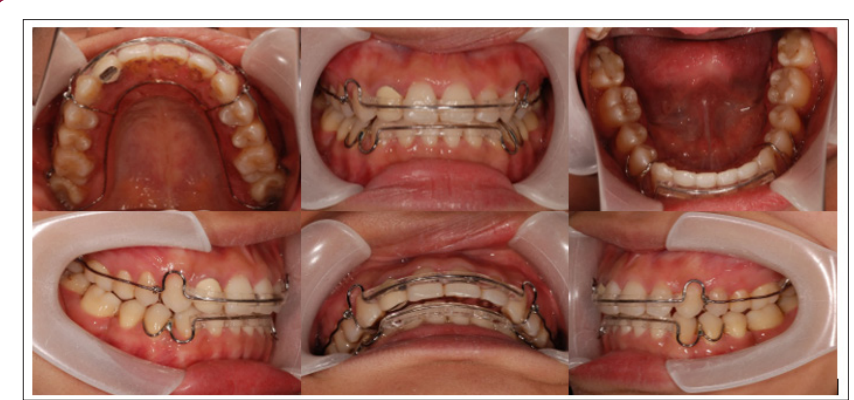

Figure 13: Period of active treatment: 18 months.

For the total treatment time of 12 months, a stable occlusion was achieved, and the asymmetrical appearance improved after the treatment (Figures 14-19).

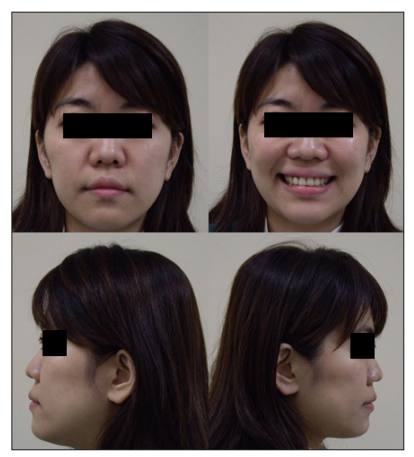

Figure 14: Facial photos after active treatment.

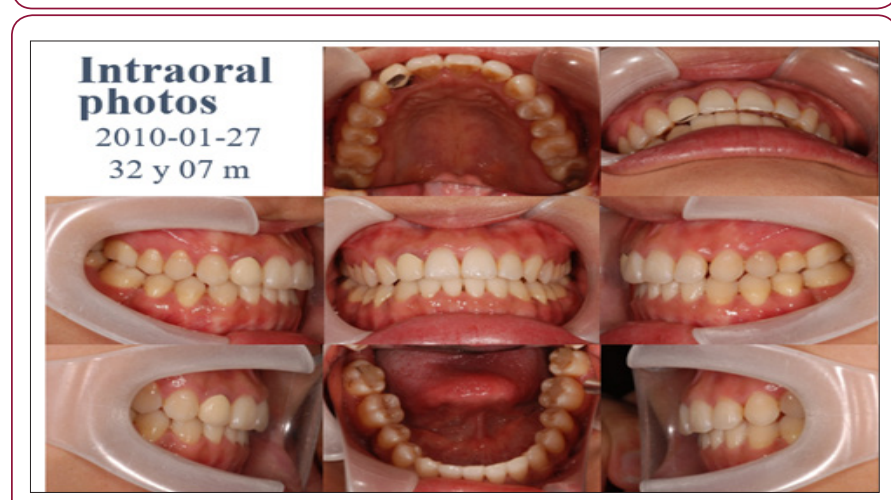

Figure 15: Intraoral photos after active treatment.

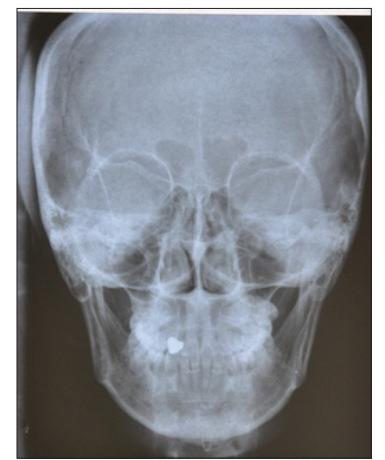

Figure 16: Postero-anterior (PA) film after active treatment.

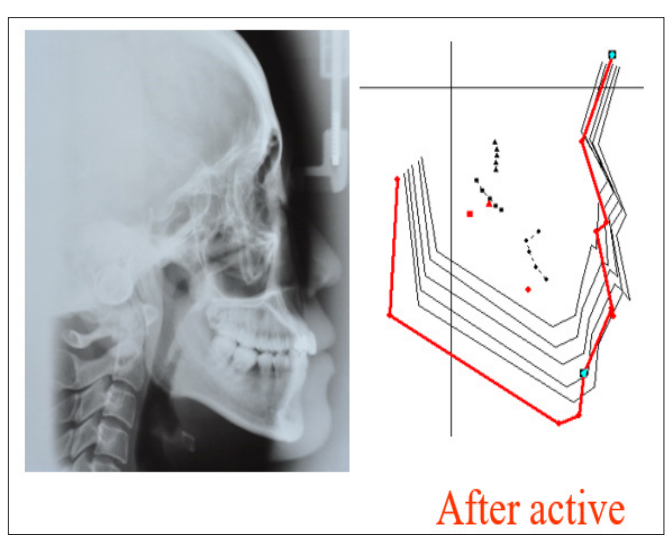

Figure 17: Lateral Cephalometric film after active treatment.

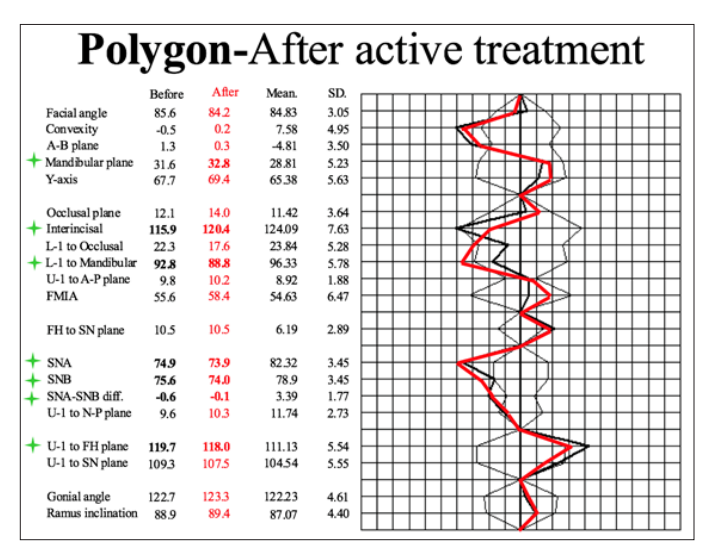

Figure 18: Polygon after active treatment.

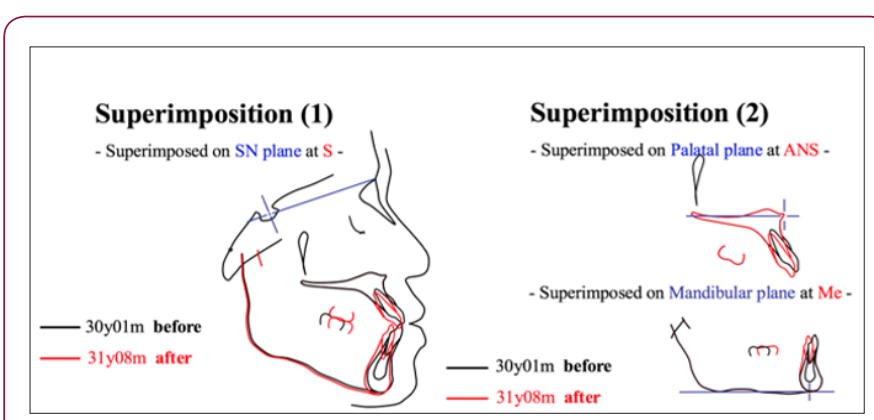

Figure 19: Superimposition after active treatment. 
After a retention period of 6 months by a functional appliance to maintain the intermaxillary relationship and to adjust the musculature tension, a new balanced facial appearance was observed.

\section{Discussion}

Treatment of Class III case is always a challenging scope of orthodontics in its difficulty and time consuming. The key element to achieve a successful therapy lies exactly in differentially diagnosing a Class III case as dental/functional or skeletal problem. This case showed true skeletal Class III from her cephalometric analysis. After 18 months of non-surgical orthodontic treatment, her poor arch coordination was corrected [7-13].

\section{Length and Width Change of Lower Arch}

When using ISW for molar mesial drive, there are space closure effect and toe in effect. These two effects aided in better molar relationship and stable interdigitation (Figure 20).

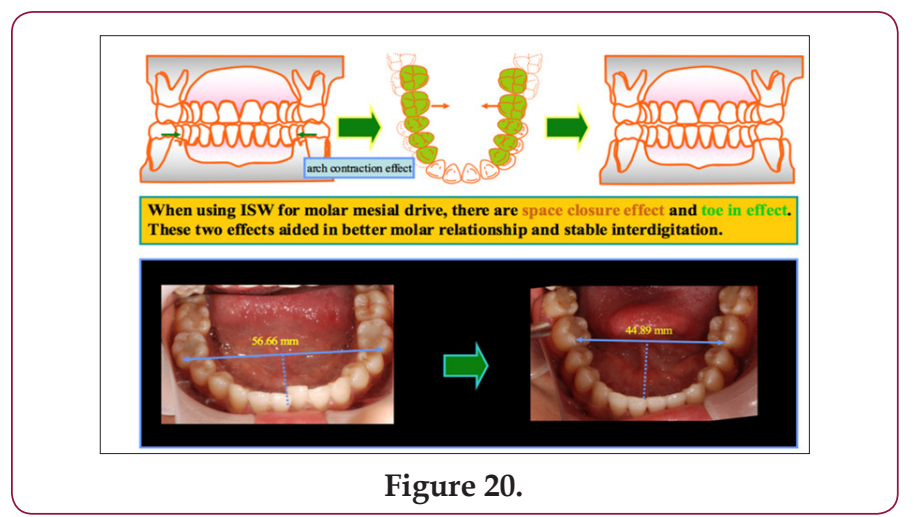

\section{Torque Control (Offset) During 37,47 Mesial Drive}

The time interval for molar mesial drive was shown on Figure 21. After 2 months of active treatment considered stable. After $6^{\text {th }}$ months of active treatment, 37,47 lingual tipping was corrected by off -set. And when it steps to 11th months after active treament, lingual tipping was under control (Figure 21).

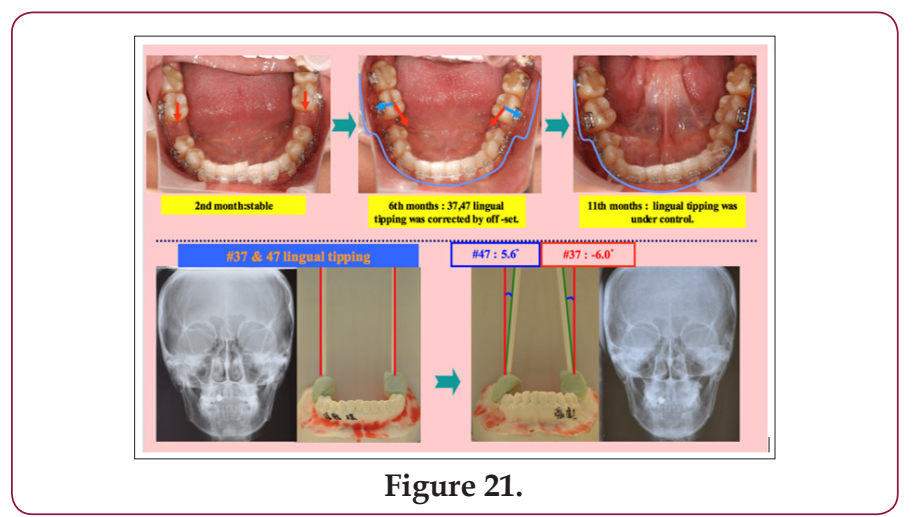

Torque Control (Use the Reverse Torque Bracket --0.018 Slot) During 37,47 Mesial Drive

After 12th months of active treatment, 37,47 remains lingual tipping, re-DBS $37,38,47,48$ with upper brackets was performed and $0.018 \times 0.025$ ISW (full size) was placed for better torque control. And for 18th months of active treatment, the lingual tipping was corrected obviously (Figure 22).

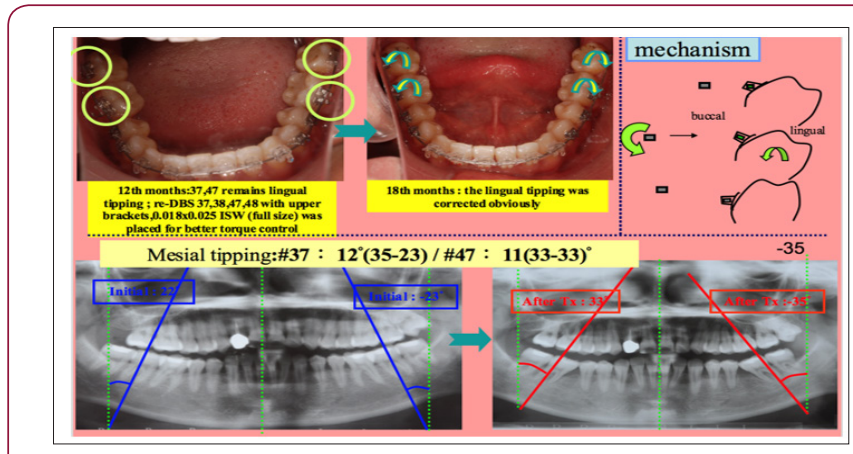

Figure 22.

\section{Effect of Intermaxillary Elastics (IME)}

For the comparison of intermaxillary elastics (IME) effect, 8 months after active treatment was the uprighting effect. While 9 months after active treatment demonstrated the mesial drive effect, 12 months and 15 months of intermaxillary elastics (IME) showed significant phenomenon of interdigitation effect and bite control (extrusion) effect (Figure 23).

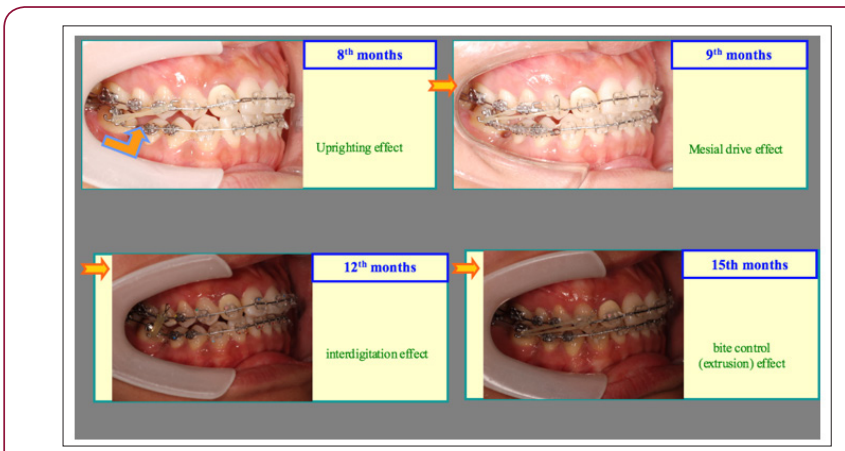

Figure 23.

\section{Conclusion}

This case showed skeletal Class III malocclusion with bilateral posterior crossbite. Poor arch coordination results in difficulty in chewing food well. In answer to this patient's decision, non-surgical treatment was adopted. With successful width decrease of lower arch by two 1st molars extraction; then mesial drive of two 2 nd and 3rd molars with closed coil spring, Class III malocclusion was corrected by ISW technique combined with Class III elastics. After 18 months of active treatment, a normal occlusion and a desirable cusp interdigitation were achieved. Therefore, adult posterior crossbite with mild crowding combined with skeletal class III tendency can be treated with LH treatment.

\section{References}

1. Kim BI (2011) Comparison of overjet among 3 arch types in normal occlusion. American Journal of Orthodontics and Dentofacial Orthopedics 139(3): e253-e260.

2. Lee YC, YC Park (1987) A study on the dental arch by occlusogram in normal occlusion. Korean Journal of Orthodontics 17(2): 279-287.

3. Bemstein N (1935) The problem of interrelation between coordination and localization. Arch Biol Sci 38: 1-35.

4. Kook YA (2009) Overjet at the anterior and posterior segments: three-dimensional analysis of arch coordination. The Angle Orthodontist 79(3): 495-501. 
5. Bayome M (2011) New clinical classification of dental arch form using facial axis points derived from three-dimensional models. Australian orthodontic journal 27(2): 117-124.

6. Cordato MA (1998) A simple mathematical study of anterior dental relations: Part III, Incisor and canine overbite. Australian orthodontic journal 15(2): 75

7. Ay S (2006) Changes in mandibular third molar angle and position after unilateral mandibular first molar extraction. American Journal of Orthodontics and Dentofacial Orthopedics 129(1): 36-41.

8. Çağlaroğlu M (2008) Effects of early unilateral first molar extraction on skeletal asymmetry. American Journal of Orthodontics and Dentofacial Orthopedics 134(2): 270-275.

9. Chugh VK (2010) Brodie bite with an extracted mandibular first molar in a young adult: A case report. American Journal of Orthodontics and Dentofacial Orthopedics 137(5): 694-700.

ISSN: 2574-1241

DOI: $10.26717 /$ BJSTR.2018.08.001590

Chih-Chieh LIN. Biomed J Sci \& Tech Res

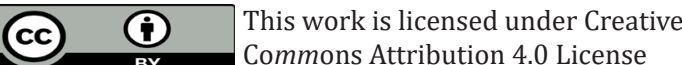

Submission Link: https://biomedres.us/submit-manuscript.php
10. Halicioglu K (2014) Effects of early unilateral mandibular first molar extraction on condylar and ramal vertical asymmetry. European journal of dentistry 8(2): 178-183.

11. Byrn BL (1995) An evaluation of mandibular asymmetry in adults with unilateral posterior crossbite. American Journal of Orthodontics and Dentofacial Orthopedics 107(4): 394-400.

12. Pinto AS (2001) Morphological and positional asymmetries of young children with functional unilateral posterior crossbite. American Journal of Orthodontics and Dentofacial Orthopedics 120(5): 513-520.

13. Telli A, S Aytan (1989) Changes in the dental arch due to obligatory early extraction of first permanent molars. Turk ortodonti dergisi: Ortodonti Derneg nin resmi yayin organidir Turkish journal of orthodontics 2(1): 138-143.

$\begin{array}{ll}\text { BIOMEDICAL } & \text { Assets of Publishing with us } \\ \text { RESEARCHES } & \text { Global archiving of articles } \\ & \text { - Immediate, unrestricted online access } \\ & \text { - Rigorous Peer Review Process } \\ & \text { - Authors Retain Copyrights }\end{array}$

